\title{
CAS E
}

OP

\section{ERECTILE TUMOUR}

IN THE POPLITEAL SPACE.-REMOVAL.

By ROBERT LISTON, EsQ., F.R.S., SURGEON TO UNIVERSITY COLLEGE HOSPITAL.

READ MARCH $14 \mathrm{TH}, 1843$.

Charles Reason, æt. 10, admitted into University College Hospital, January 2, 1843, under Mr. Liston; is a stout, remarkably healthy looking lad, an errand boy, residing in the county of Essex. He has always enjoyed good health. He was sent to the hospital on account of a swelling in the right ham, which first attracted attention about eight years ago. It was then of small size, and appeared to occasion the child no inconvenience. It continued gradually, though slowly, to increase, and about a year subsequently to its first discovery his mother showed it to a surgeon. 
At this time it is stated to have been as large as a turkey's egg, elastic to the touch, and to have had a distinct pulsation, but no 'bruit' could be heard. A grooved needle was passed into it " very deeply," to use the words of the surgeon who saw the case, but without being followed by the escape of any fluid, either pus or blood.

The disease continued slowly to increase, but still occasioned no inconvenience. About three years ago a seton was passed through a portion of it, and retained some days. A discharge having been established, the seton was withdrawn, when the openings soon healed. This proceeding had no effect in diminishing the size of the swelling. The application of blisters and iodine was now had recourse to, but equally without effect. The tumour, in fact, has been gradually enlarging up to the present time. No pain whatever has been experienced till within the last few months, and then only occasionally. The boy cannot give a very distinct account of his sensations, but says, " his leg sometimes pains him."

There is now a tumour of an oval shape, the long diameter being in the direction of the axis of the limb, situated in the upper part of the right popliteal space.

The swelling is about $3 \frac{1}{2}$ inches in length. The integuments covering it are not inflamed or discoloured, but perfectly natural. No pulsation is perceptible in it, nor can any ' bruit' be detected by the ear. The pulsation of the artery can be felt in the 
popliteal space below the tumour, and those of the anterior tibial of the affected limb are natural. No pain is complained of in the limb at the present time, and there is no tenderness of the parts on handling them. The temperature is the same as that of the opposite side.

The tumour itself has a doughy, elastic feel, giving, when the limb is extended, a sensation much resembling the fluctuation that is produced by deeply-seated matter. When the limb is flexed, however, this sensation is less distinct, and the tumour has more the feel of an elastic solid mass, which is pretty moveable, and may be distinctly raised and separated from the bone.

Mr. Liston entertained the opinion that it was a solid tumour, possibly of a fatty nature, and decided upon its removal. In this opinion Messrs. Quain and Morton coincided.

Operation, Jan. 6th.-The patient was placed on the operating table on his face. Mr. Liston then proceeded to make an exploratory puncture into the tumour. This was done by introducing a narrow bladed bistoury at the most prominent part of the swelling, nearly in the centre of the limb, and towards the upper part of the popliteal space, deeply into the mass, turning it half round on its axis, and then withdrawing it a little. This was followed by a stream of dark-coloured blood projected with some degree of force, which, however, gradually became less. The blood still continued to flow copiously, but uninterruptedly, and without any jerking. 
On attempting to move the point of the knife laterally, it was found not to be loose, showing that it had not entered any cavity. The tumour diminished somewhat in size during the escape of the blood, which might have amounted in quantity to three ounces.

It was suggested by Mr. Quain that possibly the bleeding resulted from the external saphenous vein being wounded, as in a not uncommon variety it enters the deep vein much higher than usual, in which case its situation would not be far distant from the point of puncture. The bleeding from the opening was stopped by the finger, and a second puncture made on the outer side of the tumour. This was not followed by any bleeding. Mr. Liston determined on removing the morbid growth. A free incision was made through the skin to the extent of about four inches. It was not adherent to the deeper parts. The fascia was now divided to an. equal extent, and the surface of the tumour exposed. It had much the aspect of a fatty tumour, but its size was evidently much less than before the commencement of the operation. The opinion that the vein had been opened was now seen to be incorrect.

The dissection was commenced on the outer side. The popliteal nerve was soon exposed, and the tumour, which was slightly adherent to it, carefully removed from it. After a troublesome dissection deep into the popliteal space, the tumour was found to be covered by muscle. The dissection was next 
proceeded with on the inner side, when it was soon found to be in like manner covered by muscular tissue, which was seen to be the semi-membranosus muscle embracing the tumour. During the manipulations necessary in this dissection the tumour has become much smaller than when first exposed on the division of the fascia. The substance of the semimembranosus muscle was now cut into, and the morbid growth removed. The popliteal artery was not exposed in the course of the dissection. Only one vessel required ligature, and the patient was carried to bed, the wound being covered with lint dipped in cold water. A good deal of blood was necessarily lost during the operation, and the boy was somewhat faint.

About three hours after the operation, some hæmorrhage occurred from the upper extremity of the wound, proceeding from a vessel very deeply situated. As the patient was still in a state of faintness, no attempt was made to secure the vessel, but the wound was plugged with dossils of lint. This effectually stopped the bleeding, and it did not recur. The limb was placed in a semiflexed position supported by pillows.

The lad gradually recovered from the state of faintness without the use of any stimulants. On the day following the operation he was doing well, and without bad symptoms of any kind.

Jan. 11th.-The lint having now become quite loose, it was removed, and the wound dressed with zinc lotion. 
Jan. 12th.-Edges of wound slightly approximated by means of a roller lightly applied.

Jan. 14.-Wound granulating well, and diminishing in size. The boy was directed to straighten the limb as much as possible, to prevent permanent contraction.

Feb. 1st.-The wound has been steadily filling up, and nothing now remains but a superficial sore. This looks healthy, and is cicatrizing fast under the use of the lotion. The lad walks about the ward, and has the complete use of the limb.

Examination of the Tumour.-On making a section, the tumour was found to consist of a mass of most perfect erectile tissue as large as a hen's egg. This was completely surrounded by condensed cellular and fatty matter. One part of the erectile tissue was more condensed than the rest, possibly where the seton had traversed it.

Microscopic examination of the Tumour.-Under a low power it appeared to consist of an interlacement of columns having a fibrous aspect, covered by a smooth membrane, and representing in miniature the appearance of the musculi pectinati of the auricles of the heart. Thin valvular projections of the smooth investing membrane partially closed some of the openings between the columns. Small vessels, filled with blood, were seen running in the substance of the columns. The intimate structure of these columns, examined under a higher power, was seen to consist of bundles of waved parallel filaments. The surface of the columns was covered by a deli- 
cate squamous epithelium resembling that found on the inner surface of veins. No fibres resembling those of elastic tissue could be detected.

The foregoing case is submitted with great deference to the Society, as exhibiting (in the author's opinion) some points of interest. The difficulty of forming a correct diagnosis, it may, perhaps, be admitted was considerable. The tumour occupied an important locality. It had at one time pulsated distinctly, but on the other hand it had been punctured, and a seton had been passed through the morbid mass without any considerable flow of blood having taken place.

It communicated in some degree the feeling of an encysted swelling. The duration of the disease forbade the idea of its being a chronic abscess; but it might possibly have been a cyst containing glairy or other fluid. This cyst might have been supposed to be either single or multilocular. It was, however, thought to be a solid or sarcomatous tumour of some kind, and its removal was determined upon.

The exploratory punctures made in the operating theatre did not throw much light on the case, excepting in so far that confirmation was given to the notion of the swelling being solid. The second puncture must have somehow passed the mass of erectile tissue, and entered only the surrounding fatty matter.

The considerable decrease in the size of the swelling after the incisions was not a little puzzling. 
Besides this, the appearance of the tumour, covered on all sides by muscular fibres, added much to the uncertainty and difficulty of diagnosis in the case.

The bleeding during the operation itself was inconsiderable, and but one vessel required ligature after its completion. There was, indeed, some considerable hæmorrhage a few hours afterwards, but this was easily arrested by pressure, in consequence unquestionably of the disease having been removed or cut out and not cut into.-The difficulties and dangers of the case would probably have been much increased, and the result might possibly have been very different, had the erectile tissue been encroached upon during the operation.

The case, it is presumed, is a rare and uncommon one. Erectile tissue is not often met with in parts deeply placed, notwithstanding what has been said and written by some observers about its occurrence in bones, \&c. \&c.

The author is not aware of its having been found in muscular substance. In the preceding case, however, it is more than probable that a small mass of erectile tissue had originally existed in the muscle, and had gradually become developed, till at two years of age it attained such a size as to attract attention.

Structural disease of any kind in muscle is indeed but rarely encountered; and it may, therefore, be permitted in this place to make reference to a case which occurred in the hospital practice of the au- 
thor many years ago, in which the sterno-mastoid muscle was the seat of a tumour of a nature which some respectable pathologists would perhaps class with abnormal erectile tissue. It was certainly very vascular, but contained besides much cancerous looking matter, and was altogether what Mr. Pott might have denominated "a strange distempered mass."

The circumstances of the case are shortly as follows.

The author may be allowed to premise that he would not willingly seek an intimate acquaintance with another such " tumor mali moris," so situated and so connected, notwithstanding the completely favourable result of the operation in the case in question.

Abridged from the Journals of the Royal Infirmary of Edinburgh.

John Ross, æt. about 40, was admitted August 15, 1832, into the Royal Edinburgh Infirmary, with a tumour on the left side of the neck. He has been blind from infancy in consequence of small pox. He is a musician by profession, and has latterly found it inconvenient to place his violin upon his neck, from the position of the tumour.

He states that the present disease has existed 
four years; that when he first noticed it, it was as large as a hen's egg; that he applied oil and hartshorn to it, and thought it became smaller; that it again increased, and at different times he has applied antimonial ointment, mercurial plaisters, and an ointment containing caustic potass, but all to no purpose; that within the last six months it has greatly increased. $\mathrm{He}$ is also subject to severe sciatica of the right limb, which has existed for the last six months. Is in rather indifferent health, has profuse sweats, respiration hurried, bowels irregular and costive, pulse pretty good; has an unhealthy aspect; always has some pain in the tumour, but not to any great degree. Deglutition is not impeded by it. He suffers much from the sciatica, and in consequence of it trails his right foot after him. About a month back he had retention of urine, which was relieved by the use of the warm bath and aperient medicines.

The tumour is about the size of a small turnip, but of more irregular figure ; it is hard and unyielding; very firmly bound down, and immoveable. It is bounded behind by the trapezius, above by the ramus of the jaw and its angle, below by the clavicle, and to the inner side by the sterno-mastoid muscle. No fluctuation can be felt. The surface of the tumour is not vascular, but there is one discoloured spot caused by the use of potass.

It is doubtful whether or not the sterno-mastoid muscle is involved in the disease, as only the sternal origin can be felt, and then only traced as far as the

VOL. XXVI. 
tumour. It is difficult also to say whether any lobes dip down behind the fascia of the neck.

Not being in a good state of health when admitted, he was kept in the house till the 29th, before anything was done to the neck. During this time he had some antimonial ointment applied over the sciatic nerve as it emerges from the pelvis. He had also occasional warm baths and opiates to relieve pain. From these measures he experienced some little relief, and having made up his mind to have the tumour removed, the operation was performed on the morning of August 29.

The operation was commenced by making an incision about two inches from and to the inner side of the acromion upwards to the middle of the ramus of the jaw, and another in the course of the sternomastoid, crossing the other at right angles about its middle. The flaps thus formed were dissected back, and the lower origin of the sterno-mastoid divided, this muscle being incorporated with the tumour. The dissection was very difficult, tedious and protracted, in consequence of the firm adhesion of the parts, and of the close vicinity to parts of great importance. The sheath of the vessels of the neck was denuded for at least two inches, and the cervical nerves exposed, and some of them divided. A lobe of the tumour dipped behind the clavicle: this was carefully dissected from the neighbourhood of the subclavian artery. Above, the tumour was attached to the inferior margin of the parotid, and more internally very firmly to the hyoid bone. In 
removing it from this last point, a branch of the superior thyroid artery was wounded, which it was found very difficult to secure, and this could only be done by passing a tenaculum behind the vessel, including the artery and a quantity of the surrounding substance, and then cutting the tenaculum in two, leaving a small portion of it thus fixed.

There was a considerable quantity of blood lost, chiefly venous, perhaps $1 \frac{1}{2}$ or $2 \mathrm{lbs}$. Five vessels were secured, the ends of the ligatures being cut off close. The upper angles of the wound were brought together by three sutures, and the lower part filled with lint, at the same time that pressure was made by means of a roller passed over the shoulder and round the waist.

On being raised to be carried away he fainted, but was speedily restored. He was immediately put to bed. A cold perspiration soon broke out, and he complained of his feet being very cold. Warm bottles were applied, and 40 drops of solution of morphia given.

Three o'clock, p.m.-Heat of body returning, and is on the whole as well as could reasonably be expected; he has no very severe pain; pulse rapid and small; no hæmorrhage, but some weeping or serous discharge.

Six o'clock, p.m.-Continues improving; bowels have not been opened since yesterday; ordered to take some tea and eggs; to repeat the anodyne at bed-time, and to have 3 ls of sulphate of magnesia to-morrow morning, to be repeated if necessary. 
August 30, 7 p.m.-Had a comfortable night ; nearly free from pain, and slept for a considerable time; two doses of sulphate magnesia were taken, which produced two evacuations; he complains of some nausea, and slight difficulty of deglutition, and of considerable pain in the leg, but none in the neck; skin moist ; to repeat the anodyne at bed-time.

He continued to go on very favourably, taking nourishing diet. On the third day after the operation the sutures and greater part of the lint were removed, and the wound was looking remarkably healthy. The remaining portion of lint was removed on the 5th day. On the 6th day a slight attack of erysipelas of the head and face came on. This was combatted by fomentations, punctures, and antimonial salines, and entirely disappeared in four days. The wound rapidly healed, being dressed in the centre with charpie, and with simple dressing at the edges. The man was discharged perfectly cured on the 17th of October. The sciatica, how.ever, still continued to trouble him much, and there appeared little prospect of his being entirely relieved of that affection. 